\title{
The Influence of Value Orientations in Curriculum Decision Making
}

\author{
Catherine D. Ennis
}

\begin{abstract}
Value orientations play an important role in secondary physical education curriculum decision making by influencing the teacher's curriculum content priorities relative to student needs and interests, school context, and subject matter goals. Five value orientations mediating curricular decisions in middle and high school settings have been identified as disciplinary mastery, learning process, self-actualization, social reconstruction, and ecological integration. Curriculum research conducted to examine the value orientations of secondary teachers supports the diversity of educational value orientations in physical education. Diversity may be reflected in teachers' goals for student learning and expectations for performance. Sensitivity to the diversity in teachers' educational belief systems may enhance preparation of future secondary teachers and encourage in-service teachers to become more actively involved in planning and teaching with an increased focus on student learning.
\end{abstract}

Middle and high school physical education teachers are continually involved in a deliberate process of planning and teaching that affects both the content taught and the extent to which it is learned. The process, both conscious and intuitive, takes into consideration interrelated factors that may facilitate or constrain learning. These factors include student characteristics, the learning context or situation, and the teacher's judgments, perceptions, and beliefs about the educational process. Although the formal physical education content is officially articulated in the curriculum guide, guides are not often designed to portray teaching complexity. They provide a broad array of possible content but rarely help teachers set curricular priorities. Thus, either intentionally or by default, the primary responsibility for curriculum decision making is relegated to the physical educator.

The last 30 years have brought dramatic changes in both the students and the school contexts in which secondary physical educators teach. In most public school districts desegregation required them to adjust their planning and teaching to include students from diverse cultural backgrounds. Teachers restructured their programs as a result of Title IX to accommodate coeducational classes. Public

Catherine D. Ennis is with the Department of Kinesiology, University of Maryland, College Park, MD 20742-2611. 
Law 94-142 encouraged physical educators to reorganize lessons to involve students with cognitive and physical disabilities. Physical educators also endure forced changes in their teaching assignments, moving among elementary, middle, and high school programs, as a result of shifting student enrollments. In many instances they have been required to make these changes without either input into the planning process or assistance to develop appropriate programs for these "new" students.

Although some physical educators have experienced serious problems adjusting to the evolving school environment, others have approached their teaching with a thoughtfulness and concern that appears to contribute to student learning. Peterson (1988) defines the "thoughtful professional" in terms of the "kind and quality of decision making, thinking and judgement in which the teacher engages", (p. 6). Within this definition, the physical educator's thoughts, judgments, and beliefs become central to understanding effective teaching and student learning.

Teachers make curriculum decisions based in part on a set of educational beliefs or value orientations (Eisner \& Vallance, 1974; McNeil, 1990). Value orientations integrate teachers' explicit and tacit beliefs about students and context with their knowledge of the physical education subject matter. Five educational value orientations have been postulated to influence content selection and the extent to which students master specific knowledge and performance goals in physical education: disciplinary mastery (McNeil), self-actualization (Maslow, 1979), learning process (Papert, 1980), social reconstruction (Apple, 1982), and ecological integration (Dewey, 1916).

\section{Value Orientations}

Value orientations influence a teacher's curriculum content priorities relative to student needs and interests, school-oriented socialization, and knowledge demands. Establishment of priority is central to the decision-making process in curriculum and is often reflected in guiding questions, such as What knowledge is of most worth? (Broudy, 1982; Spencer, 1860). Priority decisions are influenced in part by educational belief systems or value orientations representing competing philosophies. Each value orientation vies for priority in the distribution of resources, such as time, personnel, and facilities, in the school program. The success of any one orientation is determined by the political and social conditions in the school environment and reflects the "diversity that exists in the culture. ... One would expect that first one current [orientation] and then another should assume prominence and that, to some extent, they should all exist side by side" (Kliebard, 1988, p. 30).

\section{Disciplinary Mastery}

Disciplinary mastery has proven to be especially influential in curriculum decision making in both general education and physical education. This orientation was articulated in the writings of Herbert Spencer (1860), for whom the knowledge of most worth was the scientific knowledge base representing the core that all students must master to be considered educated. Disciplinary mastery has evolved to include a wide range of theoretical and practical knowledge, including knowledge of performance. Currently in physical education, disciplinary mastery advocates emphasize physiological and biomechanical knowledge. The definition 
of physically educated individuals as both skilled and fit reflects the knowledge base that informs the acquisition of skill and the components of fitness. The curriculum emphasis, also articulated as sport knowledge and proficiency, is a natural extension of the knowledge base (Siedentop, Mand, \& Taggart, 1986). The disciplinary mastery orientation exerts a powerful influence in physical education, as evident in the strong commercial market for textbooks with skill, fitness, and sport themes. The orientation is the focus in most teacher education programs and staff development workshops. Disciplinary mastery is also the dominant value orientation in the NASPE Outcome statements (1992), with over half representing an emphasis on proficiency or competence in the performance/ cognitive knowledge base reflected in skill, sport, and exercise.

\section{Self-Actualization}

Spencer's (1860) emphasis on science as the primary curriculum focus was an attack on the humanistic studies or child-centered curriculum that was popular at the time. The child-centered emphasis continues to influence educational decision making and is often described in curriculum literature as the selfactualization value orientation (Maslow, 1979; Rogers, 1983). Advocates place the curriculum focus on nurturing student growth. Learning is guided toward selfunderstanding with an emphasis on autonomy, self-direction, and responsibility as valued outcomes. The curriculum decision maker is free to include topics from a wide range of possibilities. Each topic is selected for its immediate relevance to students and potential to foster growth. The flexibility to select or delete curriculum components directly contrasts with the disciplinary mastery focus on content preservation, transmission, and mastery. In middle and high school physical education, self-actualization advocates may use sport and fitness content as a means of enhancing the student's self-concept, self-responsibility, and concern for others (e.g., Hellison, 1985).

\section{Learning Process}

Kilpatrick (1918) expanded the child-centered orientation to emphasize the role of active learning in understanding and retention. Learning process advocates make learning interesting and enjoyable by emphasizing each student's role in problem solving, with the student's understanding and ability to apply and synthesize information from the knowledge base essential to success. In classes taught with this orientation, students "learn how to learn" new facts by applying prior knowledge to new problems. Because tasks and problems are used as fundamental instructional tools, the teacher is released from the primary role of knowledge provider to lend assistance, ask performance-related questions, or adjust task difficulty to student ability. In physical education, the curriculum alternative proposed by Lawson and Placek (1981) exemplifies this perspective, as does the AAHPERD Basic Stuff series (Carr, 1987; Dodds, 1987).

\section{Social Reconstruction}

Social reconstruction advocates may also use problem solving to encourage students to become actively involved in learning. In this orientation, however, problem solving is socially oriented. Curriculum goals sensitive to the social, political, and economic issues in the classroom are designed to facilitate students' 
access to content and their subsequent achievement of relevant learning goals (e.g., Apple, 1982). Currently, access to opportunities for all students regardless of race, class, gender, and physical ability is a central concern of many physical educators in middle and high school programs. Students are encouraged to become actively involved in restructuring the class goals and tasks to facilitate equal opportunity. They become involved by asking questions, thinking reflectively, and developing strategies to intervene on behalf of students who are not being treated fairly. Physical educators use traditional sport, skill, and fitness content to present situations where students must evaluate the fairness of rules for all students regardless of sex or handicapping condition. Researchers in this orientation (e.g., Griffin, 1985) document the effectiveness of intervention strategies to empower teachers and students to facilitate social change.

\section{Ecological Integration}

Although many value orientations emphasize the influence of one educational emphasis (e.g., knowledge base, student, society) over others, the ecological integration orientation addresses the interactive nature of school settings. It is based on a conceptualization of schools or classrooms as integrated environments where symbiotic relationships govern outcomes. The ecological emphasis assumes the presence of complex, nonlinear interactions among critical aspects of school context, student characteristics, and subject matter demands (Ennis, 1992). Unlike other value orientations, ecological integration advocates postulate a set of balanced relationships in which the educational situation determines which educational aspect is given priority in a given lesson or unit. This orientation was first articulated by Dewey $(1916,1925)$ and has been analyzed and interpreted by Colwell (1985) and Jewett and Ennis (1990). It holds promise for increased understanding of secondary physical education programs through the identification of critical interactions and junctures in the teaching-learning process (Ennis, 1992).

Although it is relatively easy to trace value orientations in the curriculum literature, it is considerably more challenging to identify and examine them in school-based decision making. It is unlikely that orientations are manifested as pure perspectives in a curriculum guide or teacher's lesson plan. Instead, because of their tacit influence throughout all phases of education, value orientations merge at an intuitive level in curriculum documents and preactive and interactive decision making. Kliebard (1988) emphasizes that the waxing and waning of value perspectives are natural occurrences reflecting social and cultural contexts. Value orientations become entwined and convoluted in the political process as compromises are negotiated in curriculum-guide writing and team-teaching arrangements. Therefore, value orientations should not be represented as the dominance of one perspective over others, but as the relative contribution or strength of each orientation in a teacher's value profile. A teacher's profile seems to develop gradually in response to numerous factors in the school context. Once established, value preferences are unlikely to undergo dramatic changes, except in response to major perturbations or changes in the teacher's personal or professional environment (Ennis, 1992). 


\section{Research to Examine Value Orientations}

Curriculum decision making typically involves choosing among several viable alternatives. The decision maker often would prefer to incorporate several topics or activities in the curriculum but is forced to choose due to limitations in time, personnel, space, or other resources. The decision maker in secondary physical education is usually the teacher, who must answer the most critical curriculum question: What outcomes are of most worth-for my students, in my teaching situation, with these opportunities and these limitations? Research must be sensitive to the philosophical definitions of value orientations as implemented in the complex school environment.

One tool that has proven useful in understanding physical education teachers' value orientations is the Value Orientation Inventory (VOI) (Ennis \& Hooper, 1988). Teachers rank items to reflect the curriculum priorities in their programs. As in actual curriculum decision making, all items are positively stated and represent viable alternatives for physical education programs.

Content-related evidence of validity for the VOI was accumulated as domain specifications (Popham, 1975) for the orientations derived from a content analysis of the curriculum literature. Items were written to represent each orientation in physical education class settings consistent with data from ethnographic field notes and interviews (Ennis, 1985, 1987). Items were evaluated for consistency with the domain specifications by teachers and curriculum specialists. Acceptable items (Ennis \& Hooper, 1988) were placed randomly in 15 sets of five items, with one item in each set representing each of the five value orientations.

The VOI is analyzed by computing the composite score of the 15 items representing each value orientation. Composite scores for each orientation are compared to cutoff scores derived from the VOI data bank grand mean to determine high and low priority for each value orientation. The data bank represents a cross-section of physical educators reflecting a variety of demographic variables (e.g., sex, years of experience, urban/rural, elementary/middle/secondary). The reliability of the VOI was estimated using Cronbach's alpha. Alpha coefficients representing each orientation are disciplinary mastery, .91; ecological integration, .91; social reconstruction, .84; learning process, .79; and self-actualization, .77.

The forced-choice format on the VOI presents both opportunities for understanding physical educators' curriculum priorities and measurement limitations that must be understood to interpret the data effectively. The format, selected purposefully to represent the curriculum decision-making process, encourages teachers to compare and prioritize curriculum alternatives that are most important in their programs. Conversely, inventories based on Likert scales permit respondents to evaluate items without setting priorities or making comparisons. Because all items may receive high or valued scores, Likert formats may be inappropriate for examining curriculum questions of relative worth. The forced-choice format, however, has systematic measurement restraints (Kerlinger, 1973) that consistently violate the independence assumption critical in many statistics (Hicks, 1970). In other words, once the respondent has assigned the highest ranking to one item in the set, the remaining four items are forced into other, less valued positions. The resulting data are ipsative (i.e., measures that are systematically affected by other measures) (Kerlinger) and represent relative findings or the item's ranking when compared to others in the set (Hicks). Ipsative data often result in negative correlations due to the instrument format. 


\section{Program Priorities}

Results of studies to examine physical educators' belief systems support the diversity of program priorities that can be represented as value orientations. We recently (Ennis \& Zhu, 1991) investigated the value orientations of 90 teachers in three school districts (enrollments of 10,000-40,000) in the upper midwestern United States. Nearly all respondents $(96 \%)$ indicated priority (either high or low) for one or more of the value orientations. The results, graphed in Figure 1, reveal that $31 \%$ placed a high priority on ecological integration (EI) and $28 \%$ on learning process (LP). The self-actualization (SA) and social reconstruction (SR) orientations each were given high priority by $25.6 \%$ of the teachers, and the disciplinary mastery (DM) orientation by $24.4 \%$. Most value orientations were negatively correlated, as expected from the ipsative nature of the data. However, DM and LP were positively correlated $(.49, p<.0001)$, suggesting that teachers gave proximal rankings (e.g., 5,$4 ; 1,2)$ to items in these orientations. Equal numbers of male and female teachers representing elementary, middle, and secondary schools were included in the sample. Both teachers and students were predominately white. Two-thirds of the teachers reported 11 or more years of teaching experience; $34 \%$ had been teaching for at least 21 years. There were no significant differences in the value orientation priorities based on sex, years of experience, or teaching level.

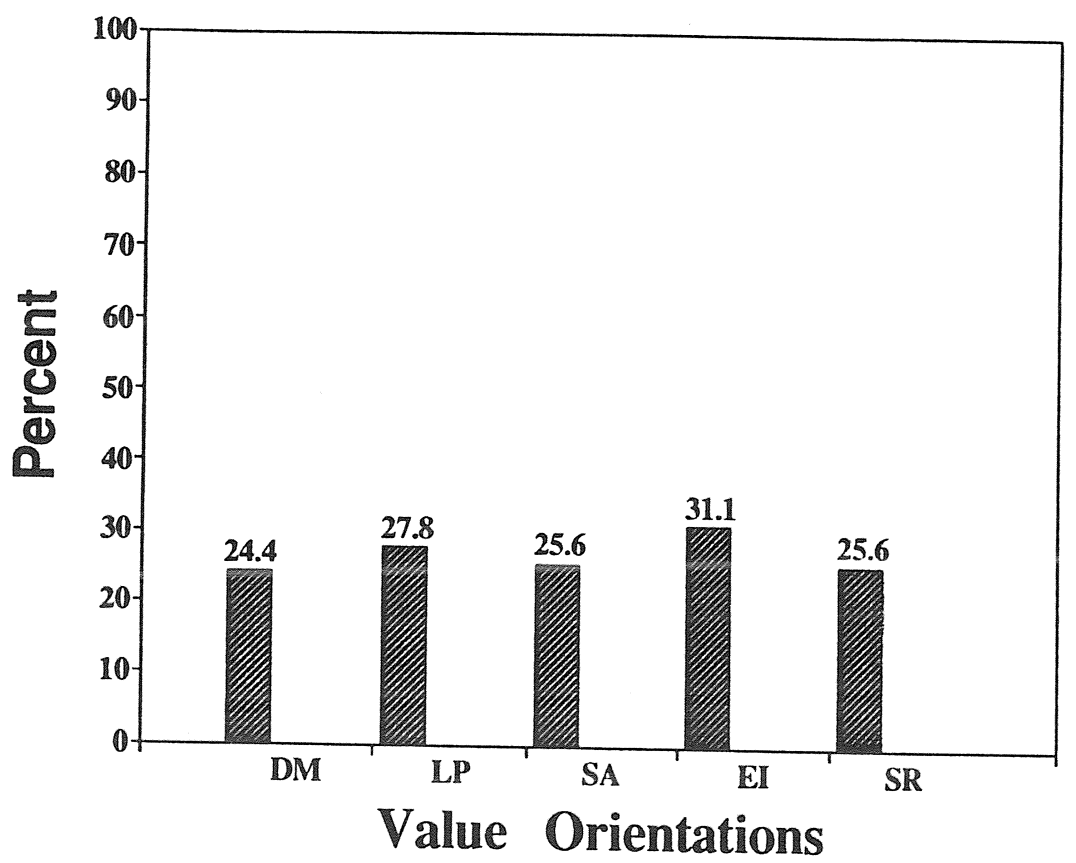

Figure 1 - High-priority value orientations of midwest physical educators. DM = disciplinary mastery; $\mathbf{L P}=$ learning process; $\mathrm{SA}=$ self-actualization; $\mathrm{EI}$ = ecological integration; $\mathrm{SR}=$ social reconstruction. 
Teachers in these predominantly white school districts expressed priorities encompassing all five value orientations. DM received a high priority ranking from only $24 \%$ of the physical educators. This was inconsistent with the strong DM emphasis on skills and sport represented in the school districts' curriculum guides. Instead some physical educators expressed priorities for process learning (LP), child-centered curriculum (SA), and equity issues (SR) as important to their physical education programs.

In a second study, we (Ennis, Chen, \& Ross, 1992) examined middle and high school physical educators' value orientations in a large urban school district (enrollment 110,000). Results indicated that the majority $(69 \%)$ of the physical educators $(n=117)$ placed one or more of the educational value orientations as a low priority. In other words, they consistently ranked several value orientations as less important in their programs. As shown in Figure 2, only one orientation, social reconstruction, received a high priority score by the majority of teachers $(57 \%)$. Conversely, low rankings were assigned to SA (78\%), DM (64\%), LP $(59 \%)$, and EI $(51 \%)$. Moderate positive correlations were detected between DM and LP $(.48, p<.0001)$ and EI and SR $(.47, p<.0001)$, suggesting that teachers gave proximal rankings to many of these items.

Only $7.6 \%$ of the physical educators placed a high priority on the DM orientation when compared to other orientations (see Figure 2). This is in contrast to the high priority placed by $57 \%$ on the SR orientation. To understand this

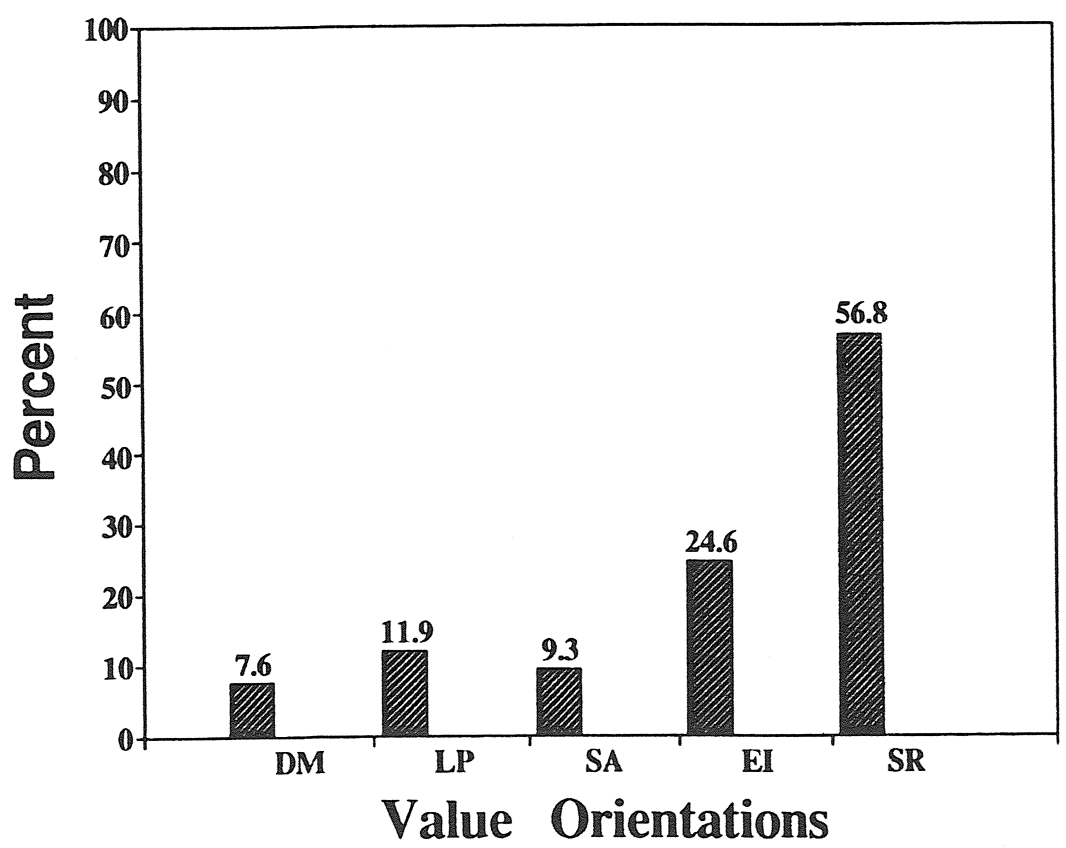

Figure 2 - High-priority value orientations of urban physical educators. DM = disciplinary mastery; $\mathbf{L P}=$ learning process; $\mathrm{SA}=$ self-actualization; $\mathbf{E I}$ = ecological integration; $\mathrm{SR}=$ social reconstruction. 
phenomenon, we must examine the characteristics of students and teachers and the teaching environment in the gym that may influence teachers' value perspectives and curriculum decisions. Students in this large school district were $78 \%$ minority, predominately African-American; physical education teachers were $80 \%$ white. Male and female teachers were equally represented, with $96 \%$ having 11 or more years of teaching experience; $61 \%$ reported 21 or more years of experience.

When most physical educators in this school district were hired more than 20 years ago, the district was composed of predominantly white, middle-class families. Minority families represented a small population, with many of those parents employed as laborers. With the passage of the Civil Rights Act and increased employment opportunities for African-Americans in local and federal government, the population of the district changed gradually as economically successful minority families moved from the inner city to this suburban school district. The proximity of the school district to a major metropolitan area with escalating incidents of violent crime resulted in concomitant increases in deviant behavior in some neighborhoods and schools (Cohn, 1992). This caused significant social problems for the local government and the school district. Increasing numbers of students were being suspended from school or disciplined for disruptive behaviors. Physical educators hired into a segregated school district in the 1960 s were now teaching students quite different from themselves and from the students they were trained to teach. Within this context, the selection of curriculum goals consistent with the improvement of the social environment may be a high priority.

\section{Comparing Content and Social Program Goals}

Follow-up research (Ennis, Ross, \& Chen, 1992) to probe the results of this study (Ennis, Chen, \& Ross, 1992) compared the curriculum goals and expectations of content-oriented teachers with those of socially oriented teachers. The groups consisted of high school physical educators who had placed a high VOI priority on both DM and LP orientations and those who placed a high priority on both EI and SR orientations. Self-reports of the DM/LP teachers collected in formal interviews indicated they designed their classes specifically to teach skills and fitness. Their instruction was often teacher-directed, with students permitted to pursue personal interests after meeting the learning goals of the class. Physical educators' goals for their high school students often followed content-oriented themes:

In the physical training program, they learn all the basic bones and muscles of the body and then they learn how to exercise each part. Once they have learned about 35 of the basic bones then we teach them the muscles that are attached. (Ennis, Ross, \& Chen, 1992, pp. 41-42)

Separate discussions with students $(n=70)$ about their teacher's goals for learning reflected a similar perspective. A student of the teacher quoted above said, "You learn about certain parts of the body ... about muscles that you probably never heard of. You learn how you can develop them, and how you can use them in sport' (p. 42). 
Teachers characterized as EI/SR stated learning goals associated with social interaction, cooperation, and enjoyment:

The number one thing that I want them to learn is socialization. Getting along with every one. I feel that if we can get them mingling with all kinds of people that the skill and the fun will come later. That's the number one thing. ... I want them [to be] friends. (p. 42)

Students in this teacher's class reported "[they] learned how to play, no matter whether you win or lose, you still have to play" and "You learn how to be athletic. You learn different games. You get a better feeling of yourself. You learn your weaknesses and your strong points"' (p. 42).

Expectations for student behavior followed closely the learning focus in each class. Self-reports of the DM/LP teachers indicated they expected students to focus quickly on the content being presented or practiced in class: "I put things on the board and when they come in, I expect them to read it and just go to work. Then I can work individually with them. I don't expect them to be horsing around" (p. 43). Students understood these expectations: "He expects us to come in and do the warm up and then do the lifts that he puts on the board. You don't horse around, you just do what he says"' (p. 43). In contrast, self-reports of teachers in the EI/SR orientation emphasized conformity to class rules, participation, and cooperation with the teacher:

I expect my students to come in here everyday dressed and prepared. As an incentive I give them [candy] at the end of each grading period for $100 \%$ dress. . . . I put their names in the school newsletter, so they know that dressing is a big part of physical education. (p. 44)

Several students in these classes emphasized the importance of dress and participation:

"At the beginning of the year she told us that every one of us are going to be treated equally. She expects us to dress every day and participate in class and be there on time and behave as if she was a parent."' (p. 44)

The self-reports of the DM/LP teachers and their students were consistent with the theoretical descriptions of these orientations presented in the curriculum literature. However, the self-reports of the EI/SR teachers were more consistent with social reproduction than with EI/SR emphasis. In each instance physical educators taught similar populations of students in similar teaching situations. Yet the DM/LP teachers emphasized the knowledge base of physical education exemplified in skill and fitness activities, whereas the EI/SR teachers focused on participation. Although the EI/SR teachers were attracted consistently to the EI and SR items on the VOI, self-reports cited instances of conformity to rules and expectations necessary for student involvement. Curriculum approaches (Banks, 1991; Hellison, 1985) and instructional strategies (Bell, 1991) typically used to encourage reflective thinking, critical questioning, and cooperative interaction were not mentioned by these EI/SR teachers.

Teacher value profiles often reflect combined perspectives from several different orientations. For example, DM/LP teachers expected their students to exhibit self-control, dress, and participate as a means to enhance skill and fitness. 
Dress and participation represented necessary but insufficient goals for physical education. The priority was increasing student performance and understanding associated with the knowledge base. The DM/LP teachers reported the use of direct teaching strategies similar to those taught in teacher preparation and staff development sessions. Conversely, EI/SR teachers used similar teacher-directed strategies with a focus on sport content as a means of enhancing positive social interaction. They reported little emphasis on fitness goals other than practicing for the twice-yearly fitness tests. The EI/SR teachers appeared to be struggling to encourage students to control themselves and to take part in the class. Although teachers reported interventions to promote fair play and access to opportunities for girls to participate in coed classes, they did not mention goals or strategies to teach students to take responsibility for monitoring these occurrences. When asked about such strategies, they were unfamiliar with curriculum approaches and methods to facilitate the teaching of EI/SR goals (e.g., Banks, 1991; Bell, 1991; Hellison, 1985).

\section{Using Value Orientations to Enhance Student Learning}

Teacher educators and staff developers can take several steps to accommodate individual differences in the educational belief systems of preservice and inservice teachers. Required courses in teacher preparation programs might include the presentation of curriculum and instructional methods consistent with several value orientations. Although curriculum approaches and teaching methods are not unique to any one value orientation, some may facilitate content implementation within particular orientations. In other words, when teachers possess a repertoire of approaches and methods consistent with several value perspectives, they are better equipped to plan and teach lessons consistent with their beliefs. When EI/SR teachers depended heavily on teacher-directed strategies (Ennis, Ross, \& Chen, 1992), they found it difficult to nurture the level of cooperative interaction they valued. Cooperative learning, problem-solving, and critical questioning strategies would help these teachers implement the goals and objectives they believed most important for their students.

Acknowledging individual differences in value orientations might also encourage teacher educators to offer more options and electives for advanced students. Preservice teachers who place a high priority on DM may find advanced courses in skill development, coaching, and sport education (Siedentop, Mand, \& Taggart, 1986) more relevant than those who are most concerned with nurturing self-esteem. These SA preservice teachers might in turn select additional courses in counseling or adolescent psychology. They might profit from opportunities to plan and teach lessons using Hellison's (1985) approach to physical education with its unique set of teaching strategies. Or, preservice teachers may demonstrate an orientation similar to that of "Ray," the student teacher in Griffin's (1985) study on sex-equity intervention. After completing a university course in sexequity, Ray worked conscientiously to intervene in a middle school program, making specific changes to promote opportunities for less-skilled students (both boys and girls) to participate. Although Griffin's strategies for intervention are important for all teachers, preservice teachers with an SR orientation are eager for information and opportunities to develop curricula sensitive to issues of race, class, and gender. However, with the current credit constraints in teacher 
preparation, it is difficult to require sufficient coursework to teach effectively in each orientation. Perhaps by providing more opportunities for diversity and responsible decision making within teacher preparation, we might better prepare future physical educators to create programs that are both consistent with their own value perspectives and sensitive to the diversity inherent in schools.

When staff developers acknowledge that physical educators' educational belief systems reflect diversity, they plan in-service sessions to accommodate a range of curriculum goals and professional interests. By specifically including sessions consistent with the value orientations of teachers with EI, SR, LP, and SA orientations as well as DM, staff developers and supervisors plan systematically to provide every teacher with new knowledge and information consistent with his or her educational belief systems. I was asked to give a session (Ennis, in press) in the urban school district where we found the strong emphasis on SR goals. Based on these findings (Ennis, Ross, \& Chen, 1992), a session was designed to target the issues that EI/SR teachers had discussed with us. The goal of the session was to provide SR teachers with information on strategies consistent with their value perspective. It was titled and publicized to attract these socially oriented teachers. Hellison's (1985) social development model was used to provide structure and specific strategies to help teachers plan and implement lessons consistent with their value orientation. The social development levels and teaching strategies were presented as Hellison has explained them, using specific examples from the interview data and observations of these teachers' classes. Comments from teachers on the district evaluation form indicated that the presentation was consistent with their value orientations and meaningful within the context of their programs. One teacher said, "Hellison's model gives uniformity and structure to programs that have been in place for years." A second physical educator said, "This was the first time in my 30 years of teaching physical education that I felt good about my own personal goals for teaching physical education. It was nice to get strategies for what I believe.'”

This staff development session was unusual because it directly targeted teachers with a specific value orientation based on the results of the VOI (see also Ennis, Mueller, \& Hooper, 1990). It was an optional session, and teachers who did not place a high priority on these issues were not required to attend. By focusing on the diversity inherent in teachers' educational belief systems, it may be possible to encourage more teachers to become actively involved in curriculum and instructional decision making. Staff development consistent with the content teachers believe is of "most worth" for their students may be critical to enhancing their abilities to increase student learning.

Teachers' educational beliefs and value orientations appear to influence their goals for student learning in secondary physical education. When examining the value orientations of physical educators, it is helpful to view their beliefs as part of a value profile. Several orientations often interact to influence the decisionmaking process. Current curriculum research is focused on the characteristics of decision making within the disciplinary mastery, learning process, and social reconstruction categories. These studies focus on the examination of curriculum decision making in context to better understand both the products of these decisions and the contextual factors that influence the process. Staff development sessions in several school districts have been designed to provide teachers the skills and information necessary to teach more effectively within their value 
perspectives. As we work to enhance teaching and learning within educationally oriented secondary physical education, acknowledgment and support of teacher diversity may provide a means to facilitate student learning.

\section{References}

Apple, M.W. (1982). Education and power. Boston: ARK.

Banks, J.A. (1991). A curriculum for empowerment, action and change. In C.E. Sleeter (Ed.), Empowerment through multicultural education (pp. 125-141). Albany: State University of New York Press.

Bell, L.A. (1991). Changing our ideas about ourselves: Group consciousness raising with elementary school girls as a means to empowerment. In C.E. Sleeter (Ed.), Empowerment through multicultural education (pp. 229-250). Albany: State University of New York Press.

Broudy, H.S. (1982). What knowledge is of most worth? Educational Leadership, 39, 574578.

Carr, N. (1987). Basic stuff: Series II. Reston, VA: American Alliance for Health, Physical Education, Recreation and Dance.

Cohn, D. (1992, March 14). Classrooms caught in the cross-fire: Armed youths at schools are more common, bolder and younger. Washington Post, pp. 1, 14.

Colwell, T. (1985). The ecological perspective in John Dewey's philosophy of education. Educational Theory, 35, 355-266.

Dewey, J. (1916). Democracy and education. New York: Macmillan.

Dewey, J. (1925). Experience and nature. LaSalle, IL: Open Court (reprinted 1971).

Dodds, P. (1987). Basic stuff: Series I. Reston, VA: American Alliance for Health, Physical Education, Recreation and Dance.

Eisner, E.W., \& Vallance, E. (Eds.) (1974). Conflicting conceptions of curriculum. Berkeley, CA: McCutchan.

Ennis, C.D. (in press). Can we really do it all? Making curriculum choices in middle and high school programs. Proceedings of the NASPE Critical Crossroads Conference for Middle and Secondary Physical Education. Reston, VA: American Alliance for Health, Physical Education, Recreation and Dance.

Ennis, C.D. (1985). Purpose concepts in existing physical education curriculum. Research Quarterly for Exercise and Sport, 56, 323-333.

Ennis, C.D. (1987). Properties of purpose concepts in an operational middle school curriculum. Journal of Teaching in Physical Education, 6, 287-300.

Ennis, C.D. (1992). Reconceptualizing learning as a dynamical system. Journal of Curriculum and Supervision, 7, 115-130.

Ennis, C.D., Chen, A., \& Ross, J. (1992). Educational value orientations as a theoretical framework for experienced urban teachers' curricular decision making. Journal of Research and Development in Education, 25, 156-163.

Ennis, C.D., \& Hooper, L.M. (1988). Development of an instrument for assessing educational value orientations. Journal of Curriculum Studies, 20, 277-280.

Ennis, C.D., Mueller, L.K., \& Hooper, L.M. (1990). The influence of teacher value orientations on curriculum planning within the parameters of a theoretical framework. Research Quarterly for Exercise and Sport, 61, 360-368.

Ennis, C.D., Ross, J., \& Chen, A. (1992). The role of value orientations in curricular decision making: A rationale for teachers' goals and expectations. Research Quarterly for Exercise and Sport, 63, 38-47. 
Ennis, C.D., \& Zhu, W. (1991). Value orientations: A description of teachers' goals for student learning. Research Quarterly for Exercise and Sport, 62, 33-40.

Griffin, P.S. (1985). Teachers' perceptions of and responses to sex equity problems in a middle school physical education program. Research Quarterly for Exercise and Sport, 56, 103-110.

Hellison, D.R. (1985). Goals and strategies for teaching physical education. Champaign, IL: Human Kinetics.

Hicks, L.E. (1970). Some properties of ipsative, normative and forced-choice normative measures. Psychological Bulletin, 74, 167-184.

Jewett, A.E., \& Ennis, C.D. (1990). Ecological integration as a value orientation for curricular decision making. Journal of Curriculum and Supervision, 5, 120-131.

Kerlinger, F.N. (1973). Foundations of behavioral research. New York: Holt, Rinehart \& Winston.

Kilpatrick, W.H. (1918). The project method. Teachers' College Record, 19, 319-335.

Kliebard, H.M. (1988). The effort to reconstruct the modern American curriculum. In L.E. Beyer \& M.W. Apple (Eds.), The curriculum: Problems, politics, and possibilities (pp. 19-31). Albany: State University of New York Press.

Lawson, H.A., \& Placek, J.H. (1981). Physical education in the secondary schools: Curricular alternatives. Boston: Allyn \& Bacon.

Maslow, A.H. (1979). Humanistic education. Journal of Humanistic Psychology, 19, 13 27.

McNeil, J.D. (1990). Curriculum: A comprehensive introduction. Boston: Little, Brown.

National Association for Sport and Physical Education. (1992). Outcomes of quality physical education. Reston, VA: AAHPERD.

Papert, S. (1980). Mindstorms: Children, computers and powerful ideas. New York: Basic.

Peterson, P.L. (1988). Teachers' and students' cognitional knowledge for classroom teaching and learning. Educational Researcher, 17(5), 5-14.

Popham, W.J. (1975). Educational evaluation. Englewood Cliffs, NJ: Prentice Hall.

Rogers, C. (1983). Freedom to learn. Columbus, OH: Merrill.

Siedentop, D., Mand, C., \& Taggart, A. (1986). Physical education: Teaching and curriculum strategies for grades 5-12. Palo Alto, CA: Mayfield.

Spencer, H. (1860). Education: Intellectual, moral and physical. New York: D. Appleton. 